\title{
PBL approach for undergraduate studies in light engineering
}

\section{Alexey Bakholdin, Vladislav Bougrov, Kseniia Ezhova, Irina Smirnova, Anna Voznesenskaya}

Alexey Bakholdin, Vladislav Bougrov, Kseniia Ezhova, Irina Smirnova, Anna Voznesenskaya, "PBL approach for undergraduate studies in light engineering," Proc. SPIE 10452, 14th Conference on Education and Training in Optics and Photonics: ETOP 2017, 104524A (16 August 2017); doi: $10.1117 / 12.2266566$

SPIE Event: 14th Conference on Education and Training in Optics and Photonics, ETOP 2017, 2017, Hangzhou, China 


\title{
PBL approach for undergraduate studies in light engineering Alexey Bakholdin, Vladislav Bougrov, Kseniia Ezhova, Irina Smirnova, and Anna Voznesenskaya ITMO University (Russian Federation)
}

\begin{abstract}
Results of the PBL approach development and implementation for undergraduate students of junior courses in the light engineering at the ITMO University are shown. Main steps of student's project activities are explained. An analysis of achieved results is provided.
\end{abstract}

Keywords: problem-based learning, project-based learning, educational technologies, learning outcomes, optical engineering, light engineering, curricula, optical education

\section{INTRODUCTION}

Key enabling technologies in photonics includes a large variety of challenges in the light engineering $[1,2]$. In particular, the light-based technologies cover research and development of photonics devices from theoretical investigations and material studies till implementation of engineering processes and production support.

The introduction of the light-based technologies and photonics devices, the rapid growth of the data transmission volumes through optical media, and the processing speed, urgent increase of the range of tasks in both scientific and in industrial and household applications require development of adequate educational technologies, provide timely response of universities to the needs of the market.

Such market demands caused development in the ITMO University of a novel undergraduate program in the light engineering purposed on training of competitive graduates in the R\&D of investigation and design of optical and optoelectronics devices [3]. The program forms skills in the area of optical information transmission, receiving, storage, processing and recognition by means of optoelectronics devices, optical design, computer image modeling, performance characterization and quality testing of optical components and devices.

The "Light Engineering" program integrates best practices, academia, and modern equipment of the ITMO leading departments - Applied and computer optics and Light technologies and optoelectronics. Project- and problem- based learning (PBL) is a specific feature of the program [4-6]. The basic idea of this approach concludes in the teaching of an expert who has got not only extensive theoretical knowledge in a certain professional field, but also able to apply this knowledge into the practice. The PBL approach is realized due to integration of students into current research and commercial projects of the departments, internships in industrial companies and scientific laboratories.

\section{PBL WORKFLOW ORGANIZATION}

Typical content of a discipline includes the study of theoretical material via lectures and its securing via classes and labs. The PBL combines the traditional approach to education, focusing on lecture component, with implemented project components, involving active practical engagement of students. In this context, the close interaction between the University and relevant industries provides the expansion of the range of the curricula courses as well as actual practical tasks. Besides, this approach gives a constant feedback, which clearly contributes to maintaining the relevance of the lecture subjects and the creation of optimal baggage of fundamental knowledge.

The distribution of activities in the curricula is shown on a diagram (Figure 1). Up to half of curricula timeline is allocated on student's selfwork and solution of scientific-practical tasks to achieve desired level of professional development and necessary learning outcomes.

14th Conference on Education and Training in Optics and Photonics: ETOP 2017, edited by Xu Liu,

Xi-Cheng Zhang, Proc. of SPIE Vol. 10452, 104524A · C 2017 ICO, IEEE, OSA, SPIE

CCC code: $0277-786 X / 17 / \$ 18 \cdot$ doi: $10.1117 / 12.2266566$

Proc. of SPIE Vol. 10452 104524A-1 
With the purpose of the professional competence growth we propose to realize PBL studies throughout the whole period of studies. According to this paradigm students are involved into the project activities from the first year of the undergraduate course.

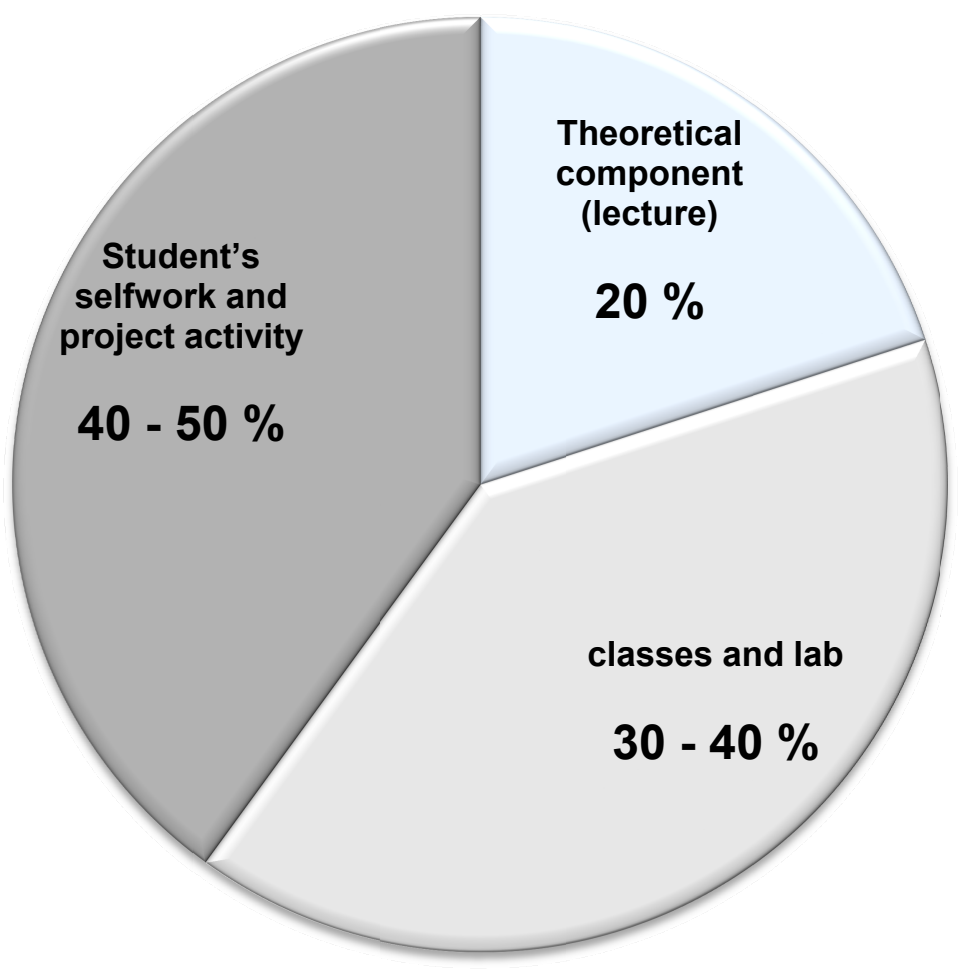

Figure 1. Term's workload

The process of the PBL approach implementation requires not only the organization of educational, industrial and other internships of students, but actively engaging them into current working groups, dealing with real projects and research.

The PBL provides the integration of students in project activities occurs at stages throughout the whole period of learning starting with the first terms of the undergraduate level (Figure 2).

Learning of project management basis and process (or product) lifecycle is proposed as introduction into the project activities. Second step of the involvement into the project activities is task statement setup. The solution of the task starts from the familiarization with the subject area. Subsequent performance suggests the search of solution methods. Expected result is a development of professional skills.

In the early stages relatively simple tasks are offered to perform, contributing to the development of necessary initial skills and early engagement of the next integration stage until the execution of complex tasks at the final stage of learning, which is strengthened with the implementation and defense of a final project. In parallel, there is adaptation of curricula and updating of educational technologies to accumulate and apply the lessons learned across the University. 


\section{STRUCTURE OF PROJECT TASKS}

Project tasks consist of the following main parts (Figure 3): 1) Preamble - short theoretical description of the problem; 2) Task - list of technical requirements; 3) Results - report and presentation; 4) Assessment - evaluation indicators and criteria.

Firstly, students study the theoretical description of the task and analyze given technical requirements. To get more information they may use any information sources. On the further stages students perform necessary calculations, modeling and experiments. The supervisor monitors intermediate results and directs the following stages.

The most complicated part of the PBL task is assessment of results. Generally the assessment concludes in evaluation using special assessment form with indicators and criteria formulated in accordance with recognized recommendations [7] (Table). For this case the most promising method is the circular assessment $\left(360^{\circ}\right.$ method, assessment-center method). This method requires that in evaluation are involved various participants of the PBL case tutor, side participants, and students themselves (Figure 4). It provides the expert evaluation approach. Finally, after processing of the assessment forms each participant receives his own estimation.

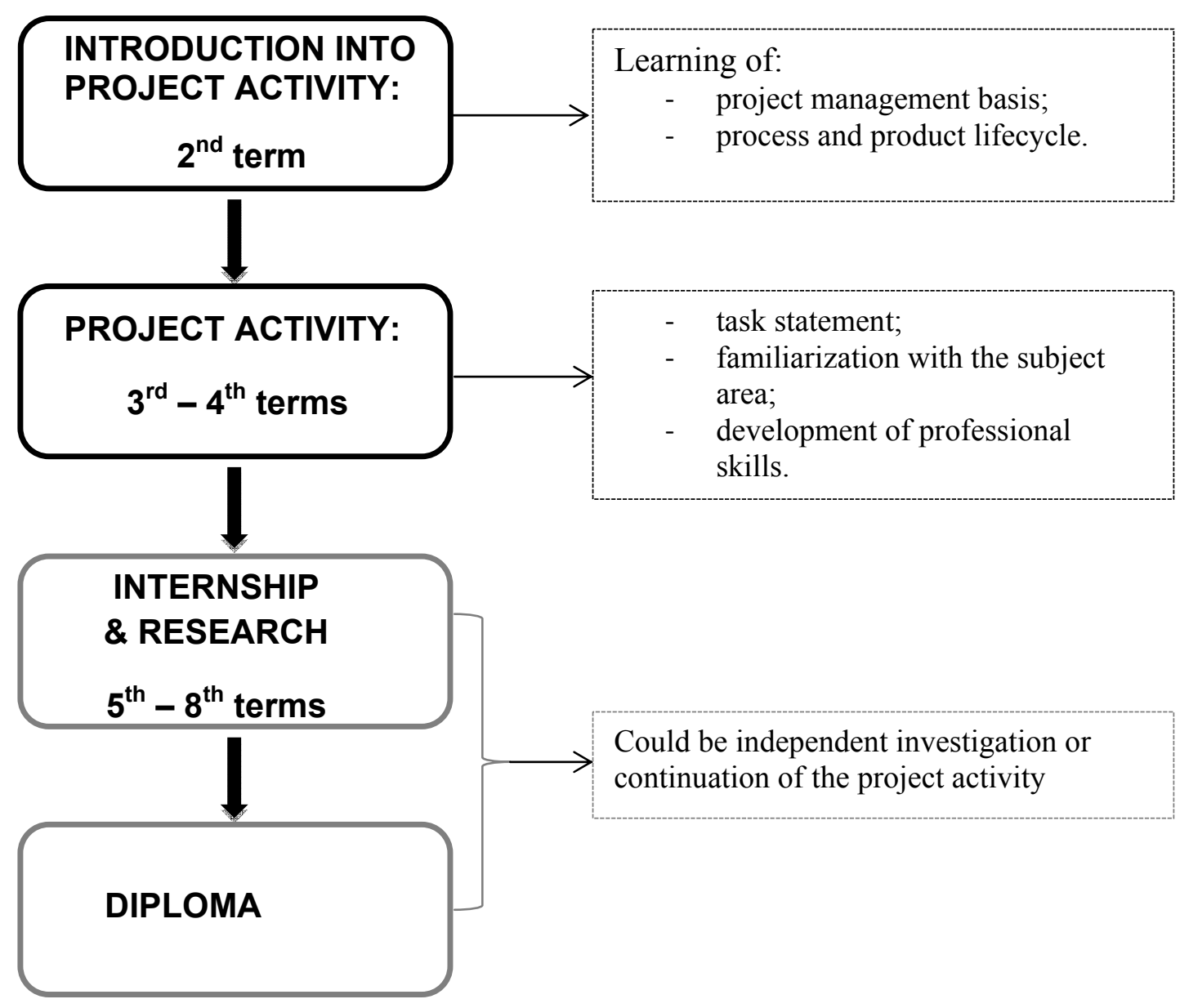

Figure 2. Project workflow 


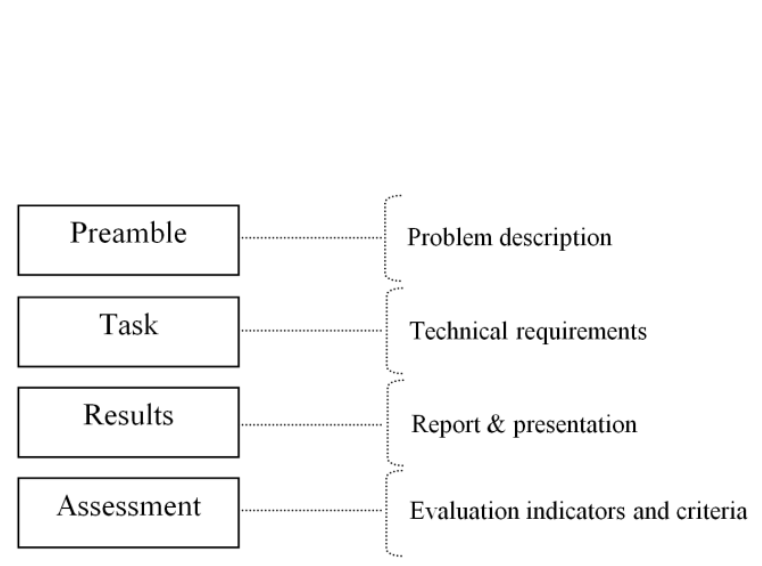

Figure 3. PBL case structure

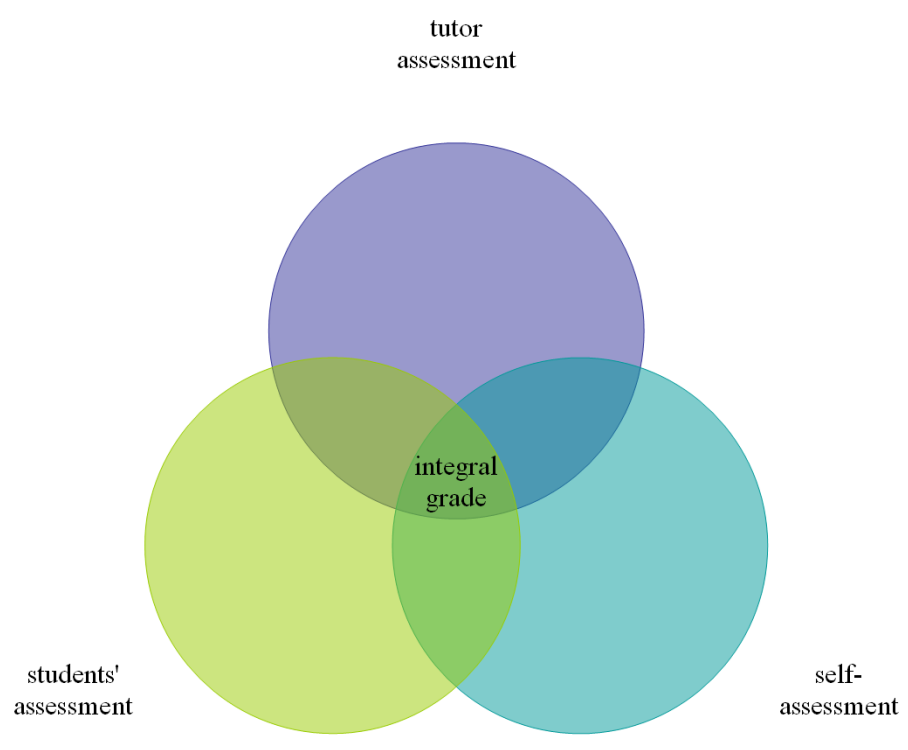

Figure 4. Circular assessment of learning outcomes

Table 1. Assessment form example

Student

Group

Expert

\begin{tabular}{|c|c|c|c|c|c|}
\hline \multirow[b]{2}{*}{ No } & \multirow[b]{2}{*}{ Indicators } & \multicolumn{4}{|c|}{ Grade } \\
\hline & & $\begin{array}{c}5 \\
\text { (excellent) }\end{array}$ & $\begin{array}{c}4 \\
\text { (good) }\end{array}$ & $\begin{array}{c}3 \\
\text { (satisfactory) }\end{array}$ & $\begin{array}{c}0^{*} \\
\text { (unsatisfactory/ } \\
\text { irrelevant) }\end{array}$ \\
\hline 1 & Analysis of information sources & & & & \\
\hline 2 & Foreign languages & & & & \\
\hline 3 & Base knowledge in professional area & & & & \\
\hline 4 & Base knowledge in neighboring areas & & & & \\
\hline 5 & Problem solving skills and research skills & & & & \\
\hline 6 & Practical skills & & & & \\
\hline 7 & $\begin{array}{l}\text { Computer technologies skills and } \\
\text { application of specific commercial software }\end{array}$ & & & & \\
\hline 8 & Reporting skills & & & & \\
\hline 9 & Public speaking skills & & & & \\
\hline 10 & $\begin{array}{l}\text { Interpersonal communication skills } \\
\text { (teamwork) }\end{array}$ & & & & \\
\hline 11 & Creativity and independent work & & & & \\
\hline 12 & Leadership & & & & \\
\hline 13 & Tolerance and loyalty & & & & \\
\hline 14 & Time-management skills & & & & \\
\hline
\end{tabular}

\section{EXAMPLES OF PROJECT TASKS}

Various project tasks may be presented to the $1^{\text {st }}-2^{\text {nd }}$ year students of the "Light Engineering" undergraduate program. In this part examples of the PBL tasks are shown. 


\section{Task 1. Design of plastic glasses for medical applications \\ Preamble}

To carry out medical operations on the fine vessels, as well as in the production of microelectronic circuits and the manufacture of jewelry used in the optical system (operating points) of a relatively small increase. For the additional accommodation of the eye during the transition from observation with and without glasses need optical system whose object and image are in one plane. Glasses feature is connected with a requirement of lack of additional accommodation of the eye during the transition from observation with and without glasses.

Figure 5 shows the operation glasses design. This can be a specially designed system that allows to change the base of the eye and the angle of convergence. But at low magnifications you can use an ordinary socket, which set the calculated optical system.

Design of the operation glasses of relatively low magnification (2 to 3 times) utilizes the Galileo system (Figure 6). Prismatic binoculars are used for higher magnification which allows the operator to observe micro details within the surgical field.

Key features of such systems are excellent indicators of field, no distortion and excessive fatigue of the eye. It could be distinguished due to the high quality of optics manufacturing. But such systems must have relatively small weight and size, while lenses made of glass much heavier construction.

Specific weight of plastic is two times less than glass, so the glasses with polymer lenses much easier. In addition, the ease of plastic allows you to use non-rimless or semi-rimless eyeglasses. Also in today's world strengthening coatings for polymeric lenses which make them as scratch resistant as mineral were developed. At the moment, glass has almost no advantages over plastic: plastic is lighter, provide shock and trauma safety. And plastic is a better material from an economic point of view.

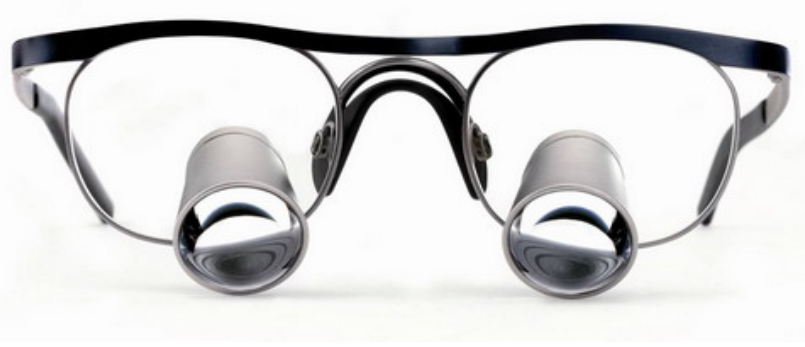

Figure 5. Operation glasses design

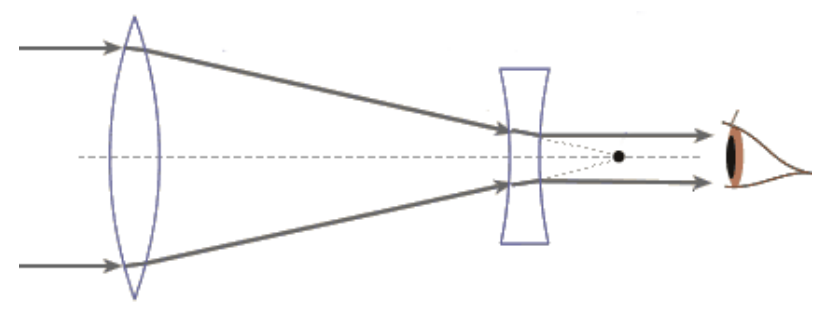

Figure 6. The Galileo system

\section{Task content}

The purpose of the task is modification of modern design of operating glasses and the replacement of a glass lenses with polymer / plastic ones.

1. To execute analysis of optical polymers and plastics and compare their optical features.

2. To perform optical design of polymer glasses of various magnification using Zemax.

3. To distinguish the best performance of glasses by means of optical system optimization.

\section{Task 2. Development of LED illumination systems}

\section{Preamble}

Currently, the LEDs used for lighting, occupied along with other sources a strong position on the market of lighting systems. LED lamps, spotlights and other lighting appliances, are widespread, actively used to create artificial lighting, decorative lighting, landscape and architectural lighting, as well as in the design of advertising objects [8]. 
LEDs are several times brighter, more durable, and more economical than halogen lamps and xenon. In addition, they do not require placement of the ballasts and making changes to the wiring. Thanks to the combination of these qualities today, many lighting devices have transferred it to the LEDs. Presently, street lights already use LED matrices (Figure 7), due to the fact that they consume much less electricity and their efficiency is several dozen times higher than halogen lamps.

In the automotive industry LED optics are particularly common in off-road technology. This is due primarily to the fact that for off-road driving regular light is insufficient, and installing halogen "chandeliers" should be replaced with the wiring of the car due to the rapidly increasing load, as the wiring and the generator. For ATVs, snowmobiles, boats, personal watercraft and scooters the use of LEDs is reasonably primarily due to the extremely low power of the generator. For agricultural, military, rescue and mining equipment the use of LEDs in combination with the secondary optics (Figure 8) allows to reach an unprecedented level of illumination, increasing the safety and efficiency of the operations.

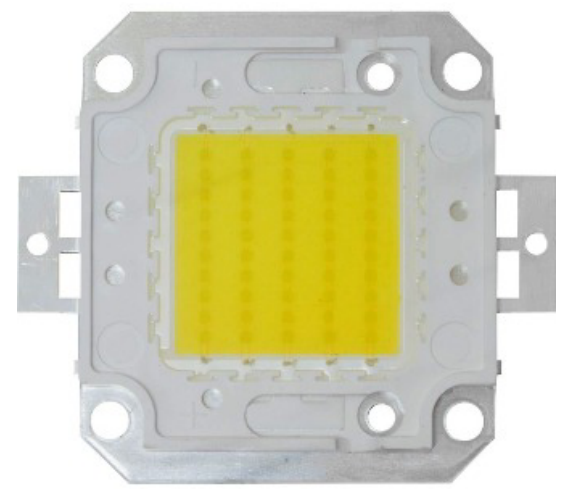

Figure 7. Example of an LED matrix

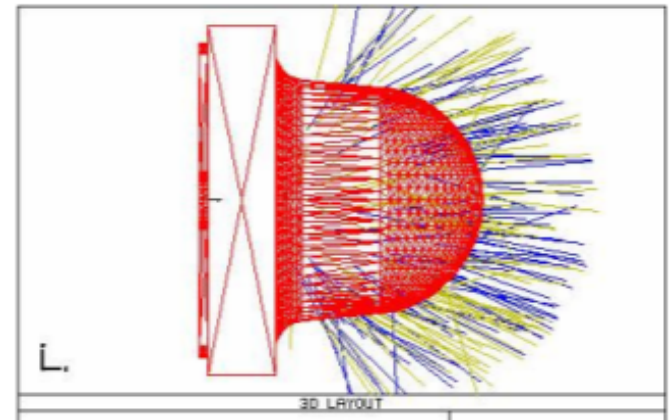

Figure 8. Computer model of an LED system with secondary optics

\section{Task content}

The purpose of the task is review and comparative analysis of the LEDs and their modeling issues.

1. To study the characteristics of white high power LEDs: Osram, Cree, Nichia etc. (2-5 manufacturers)

2. To structure the characteristics - electrical, optical, etc.

3. To choose any LED and perform a more detailed analysis of the optical performance: luminous flux, efficiency, radiation pattern, spectrum /color temperature, dependence of the light flux from the current and the operating temperature, size of the glowing venues.

4. To give recommendations/ conclusions - for what purpose some LEDs are suitable (for what type of lighting?), why (taking into account not only the optical characteristics).

5. To model LEDs in commercial tools (Zemax, etc.).

\section{Task content}

The purpose of the task is review and comparative analysis of the white light street LED lamps.

1. To study and classify the types of optical components for LEDs (lenses, reflectors, etc.). To determine advantages and disadvantages of reflectors and lenses.

2. To pick up some manufacturers of the street lamps.

3. To perform chart types of street lamps (not focus on decorative lighting and functional).

4. To determine surface profiles of secondary optics for the street lighting systems. 


\section{RESULTS}

The considered PBL tasks are started in 2016 for $2^{\text {nd }}$ year undergraduate students in Light engineering, about 20 students in total. Each student implements his or her own project and presents its results on a seminar.

Analysis of assessment results has shown that in most cases students have low self-esteem. This phenomenon may be connected with different psychological and social factors as well as lack of experience to demonstrate and apply their skills and themselves in general. Meantime, such projects are interesting for students due to possibility to demonstrate their personal abilities, participate in real professional projects and investigations, get new practical skills. Besides, these projects motivate students to deep theoretical knowledge in the field of studies as well as in neighboring fields.

More creative projects could be developed during the internship and research. As one of the main outcomes it could be represented as a final work.

In future the proposed projects will be adopted and proposed to the $1^{\text {st }}$ year undergraduate students.

\section{CONCLUSION}

In this paper features and structure of PBL tasks for students of junior courses is shown. Assessment technology of learning outcomes is presented. Some PBL tasks for the light engineering studies at the first cycle level are proposed. Results of the PBL tasks application among ITMO University students are analyzed and recommendations for further PBL dissemination are formulated.

\section{ACKNOWLEDGMENTS}

This work was supported by the Ministry of Education and Science of Russian Federation (project № 27.5615.2017/5.1).

\section{REFERENCES}

[1] Photonics Strategic Multiannual Roadmap/ http://www.photonics21.org/download/Brochures/Photonics_Roadmap_final_lowres.pdf.

[2] Anna Voznesenskaya, Vladislav Bougrov, Sergey Kozlov, and Vladimir Vasilev, "ITMO Photonics: Center of Excellence," Proceedings SPIE 9946, Optics Education and Outreach IV, 99460V (2016).

[3] Alexey Bakholdin, Vladislav Bougrov, Anna Voznesenskaya, Kseniia Ezhova, "Advanced interdisciplinary undergraduate program: light engineering," Proceedings SPIE 9946, Optics Education and Outreach IV, 994612 (2016).

[4] Anna Voznesenskaya, "Problem-based learning in optical engineering studies," Proceedings SPIE 9946, Optics Education and Outreach IV, 994610 (2016).

[5] Judith F. Donnelly, Nicholas M. Massa, "The PBL Projects: Where we've been and where we are going," Proceedings SPIE 9793, (2015).

[6] Nicholas M. Massa, Judith Donnelly, Fenna Hanes, "Student Reactions to Problem-Based Learning in Photonics Technician Education,” Proceedings of SPIE 9289 (2013).

[7] Tuning structures in educational Europe http://www.unideusto.org/tuningeu/images/stories/Summary_of_outcomes TN/AHELO_Engineering.pdf.

[8] P.S. Chechurov, and G.E. Romanova, "Using the Zemax software complex to form photometric models of LED illuminator devices,” Journ. Opt. Techn. Vol. 79, Issue 5, pp. 302-304 (2012). 